\title{
Reduced-fat Cheddar and Swiss-type cheeses harboring exopolysaccharide- producing probiotic Lactobacillus mucosae DPC 6426
}

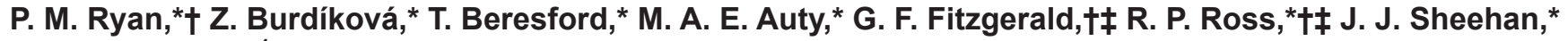 \\ and C. Stanton $\ddagger^{1}$ \\ *Teagasc Food Research Centre Moorepark, Fermoy, Ireland P61 C996 \\ †Department of Microbiology, and \\ ‡APC Microbiome Institute, University College Cork, Ireland T12 YT20
}

\section{ABSTRACT}

Exopolysaccharide-producing Lactobacillus mucosae DPC 6426 was previously shown to have promising hypocholesterolemic activity in the atherosclerosis-prone apolipoprotein-E-deficient $\left(\mathrm{apoE}^{-/-}\right)$murine model. The aim of this study was to investigate the suitability of reduced-fat Cheddar and Swiss-type cheeses as functional (carrier) foods for delivery of this probiotic strain. All cheeses were manufactured at pilot-scale (500-L vats) in triplicate, with standard commercially available starters: for Cheddar, Lactococcus lactis; and for Swiss-type cheese, Streptococcus thermophilus, Lactobacillus helveticus, and Propionibacterium freudenreichii. Lactobacillus mucosae DPC 6426 was used as an adjunct culture during cheese manufacture, at a level of $\sim 10^{6} \mathrm{cfu} \cdot \mathrm{mL}^{-1}$ cheese milk (subsequently present in the cheese curd at $\left.>10^{7} \mathrm{cfu} \cdot \mathrm{g}^{-1}\right)$. The adjunct strain remained viable at $>5 \times 10^{7} \mathrm{cfu} \cdot \mathrm{g}^{-1}$ in both Swisstype and Cheddar cheeses following ripening for 6 mo. Sensory analysis revealed that the presence of the adjunct culture imparted a more appealing appearance in Swiss-type cheese, but had no significant effect on the sensory characteristics of Cheddar cheeses. Moreover, the adjunct culture had no significant effect on cheese composition, proteolysis, $\mathrm{pH}$, or instrumentally quantified textural characteristics of Cheddar cheeses. These data indicate that low-fat Swiss-type and Cheddar cheeses represent suitable food matrices for the delivery of the hypocholesterolemic Lactobacillus mucosae DPC 6426 in an industrial setting.

Key words: reduced fat, Cheddar, Swiss type, Lactobacillus mucosae, exopolysaccharide

Received June 22, 2015.

Accepted July 28, 2015.

${ }^{1}$ Corresponding author: Catherine.Stanton@teagasc.ie

\section{INTRODUCTION}

Lactic acid bacteria (LAB) are essential to biochemical processes such as acidification and proteolysis, and selected microbes have also found uses as adjunct cultures, conferring technofunctional attributes to the product containing them, and health-promoting properties for consumers. Whereas starter LAB such as Streptococcus thermophilus and Lactobacillus delbrueckii ssp. bulgaricus have earned claims in aiding host lactose digestion (EFSA, 2010), many products claiming probiotic status lack the requirements of a clinically proven health benefit, in conjunction with the ability to survive gastrointestinal tract (GIT) transit (Hill et al., 2014). Lactobacillus mucosae DPC 6426 is an exopolysaccharide (EPS)-producing strain, previously isolated from the mammalian GIT, which has demonstrated hypocholesterolemic activity in atherosclerosis-prone mice on a high-fat diet (London et al., 2015b). Furthermore, the heteropolysaccharide that the strain synthesizes appears to afford the strain higher tolerance to heat, acid, bile, and salt stresses in vitro (London et al., 2014). These properties make Lb. mucosae DPC 6426 an ideal candidate for industrial exploitation by the functional food sector (Ryan et al., 2015b). Previous work in our group has identified the potential of $L b$. mucosae DPC 6426 as a technofunctional adjunct strain in yogurt manufacture, reducing syneresis (London et al., 2015a). As a species, Lb. mucosae are acknowledged for their GIT adhesion capabilities, expressing mucus binding protein (Mub) homologs and other adhesin-like proteins, such as the ABO blood group histone H3binding Lam29 of Lb. mucosae ME-340 (Roos et al., 2000; Lee et al., 2012; Watanabe et al., 2012; Valeriano et al., 2014). Such adherence is theorized to aid in the competitive exclusion of attaching and effacing enteric pathogens in vivo, thus reducing the opportunity for infection (Ramiah et al., 2008; Dicks et al., 2014). In addition, Lb. mucosae has demonstrated an extended transient occupation of the host when compared with 
allochthonous Lactobacillus spp., and so is more likely an indigenous species of the mammalian GIT (Frese et al., 2012).

Exopolysaccharide-synthesizing LAB, such as Lactococcus lactis ssp. cremoris DPC 6532, have previously been investigated as technofunctionally beneficial adjuncts (Costa et al., 2010). The use of these adjuncts in reduced-fat cheeses generally provides enhanced water-binding capacity, leading to higher cheese yield and a cheese more similar in texture and quality to its full-fat counterpart (Awad et al., 2005; Dabour et al., 2006; Lynch et al., 2014). Furthermore, cheese has the potential to act as a favorable matrix for $L b$. $m u$ cosae DPC 6426 survival, due to the near anaerobic conditions created by the primary starter bacteria over the initial weeks of ripening and the relatively high fat content of the cheese structure (van den Tempel et al., 2002; Lavermicocca, 2006).

In a recent study, we have shown that dietary intervention with EPS-producing Lactobacillus mucosae DPC 6426 resulted in modulation of lipid metabolism in an animal model of lipid-driven atherosclerosis. Apolipoprotein $\mathrm{E}$ deficient (apoE $\mathrm{E}^{-/-}$) mice fed a high-fat/ high-cholesterol diet, supplemented with Lactobacillus mucosae DPC 6426, resulted in significantly lower serum cholesterol and triglyceride levels compared with unsupplemented controls (London et al., 2015b). These data indicate that dietary intervention with food products containing live EPS-producing probiotic strains is a promising strategy for managing lipid metabolism. Therefore, the aim of this study was to investigate the performance of the cholesterol-lowering EPS-producing strain, Lactobacillus mucosae DPC 6426, as adjunct culture during manufacture of reduced-fat Cheddar and Swiss-type cheeses. We hypothesized that reduced-fat cheese would be an ideal food matrix for delivering this probiotic and also that the EPS produced by $L b$. $m u$ cosae DPC 6426 might improve functional properties, such as cheese texture and yield recovered, in the final product.

\section{MATERIALS AND METHODS}

\section{Strains and Growth Conditions}

The ropy EPS-producing adjunct used for both cheese types, Lactobacillus mucosae DPC 6426, was selected from the Teagasc Food Research Centre Moorepark culture collection and had originally been isolated from the mammalian GIT (Ryan et al., 2015a). The strain was rifampicin-tagged to allow enumeration in the presence of other nonstarter lactic acid bacteria (NSLAB). Lactobacillus mucosae DPC 6426 was cul- tured directly from a $-20^{\circ} \mathrm{C}$ stock on de Man Rogosa Sharpe (MRS, Difco, Unitech Ltd., Dublin, Ireland) agar anaerobically in jars with Anaerocult A gas packs (Merck KGaA, Darmstadt, Germany) for $48 \mathrm{~h}$ at $37^{\circ} \mathrm{C}$ and all subsequent cultures were grown under the same conditions in MRS broth with $250 \mathrm{mg} \cdot \mathrm{L}^{-1}$ rifampicin (Sigma Aldrich, Wicklow, Ireland) to select for the resistant derivative.

The day before cheese manufacture, Lb. mucosae DPC 6426 was inoculated at 1\% in 1,000 $\mathrm{mL}$ of MRS, containing $5 \%$ (wt/vol) sucrose to facilitate EPS production, and grown to stationary phase overnight. The cells were pelleted by centrifuging at $16,900 \times g$ for $15 \mathrm{~min}$ at $4^{\circ} \mathrm{C}$ (Sorvall Legend RT, Thermo Scientific, Dublin, Ireland, with SLA3000 rotor) and washed twice with PBS (Sigma-Aldrich). The cells were then resuspended in $100 \mathrm{~mL}$ of PBS and maintained on ice until cheese-making. The adjunct culture was added at $10^{6} \mathrm{cfu} \cdot \mathrm{mL}^{-1}$ of cheese milk or $100 \mathrm{~mL}$ of PBS for control cheeses.

The starter cultures used were Lactococcus lactis R604 (0.1 g. $\mathrm{L}^{-1}$, Chr. Hansen, Little Island, Co. Cork, Ireland) for Cheddar cheese and Streptococcus thermophilus Th3 (0.1 g. $\mathrm{L}^{-1}$, Chr. Hansen), Lactobacillus helveticus LHBO2 (0.05 g. $\mathrm{L}^{-1}$, Chr. Hansen), and Propionibacterium freudenreichii DPC 6451 (PAB, 0.007\% $\mathrm{vol} / \mathrm{vol}$ ) for Swiss-type cheese.

\section{Cheese Manufacture}

Production. Trials were conducted in triplicate over a 6-mo period. Raw milk was standardized to a protein:fat ratio of 2.19:1 or 3.48:1 for Swiss-type and Cheddar cheeses, respectively. Cheese milk was pasteurized at $72^{\circ} \mathrm{C}$ for $15 \mathrm{~s}$, and cooled to $31^{\circ} \mathrm{C}$ before cheese-making. Starter cultures were stored at $-80^{\circ} \mathrm{C}$ until required for use and adjunct cultures were kept on ice until use. Reduced-fat Cheddar cheeses were produced according to the methods of Rynne et al. (2004), and Swiss-type cheeses were manufactured according to the method of Sheehan et al. (2008), with minor modifications.

The control Swiss-type coagula were cut at gel firmness standard for the production of such cheeses as observed visually, whereas the coagula of the Swisstype with adjunct vats were cut at the same duration of coagulation. Gel firmness was measured instrumentally using the method reported by Costa et al. (2010). Swiss-type vats were then cut to $\sim 5-\mathrm{mm}^{3}$ curds and allowed a 10-min healing period before cooking. Swisstype curds and whey were cooked from 32 to $45^{\circ} \mathrm{C}$ at $0.5^{\circ} \mathrm{C} \cdot \mathrm{min}^{-1}$ and then from 45 to $53^{\circ} \mathrm{C}$ at $1^{\circ} \mathrm{C} \cdot \mathrm{min}^{-1}$. 
Swiss-type curds were drained to a pre-press vat at $\mathrm{pH}$ 6.3, molded, and pressed at pressures increasing incrementally to $35.2 \mathrm{kPa}$ before brining for $10 \mathrm{~h}$ in a saturated brine solution of $23 \% \mathrm{NaCl}$ and $0.56 \% \mathrm{CaCl}_{2}$ $\left(10^{\circ} \mathrm{C}, \mathrm{pH} 5.2\right)$.

Ripening. Cheddar was vacuum-packed and ripened at $8^{\circ} \mathrm{C}$ for 6 mo. Swiss-type cheese was vacuumpacked in $\mathrm{CO}_{2}$-permeable bags and kept at 9 to $10^{\circ} \mathrm{C}$ for $10 \mathrm{~d}$, then moved to $22^{\circ} \mathrm{C}$ for 3 wk to facilitate eye formation and back down to $8^{\circ} \mathrm{C}$ for the remaining 5 mo to retard the PAB fermentation.

\section{Enumeration of Starter, PAB, NSLAB, and Adjunct}

Cheese samples were aseptically removed at $0,1,7$, $21,35,56,70,91,119,154$, and $182 \mathrm{~d}$ of ripening. The samples were placed in a stomacher bag, diluted 1:10 with sterile trisodium citrate $(2 \% \mathrm{wt} / \mathrm{vol})$, and homogenized in a stomacher (Stomacher, Lab-Blender 400, Seward, Thetford, Norfolk, UK) for $5 \mathrm{~min}$. Further dilutions were prepared as required in maximum recovery diluent (MRD, Oxoid, Fannin Healthcare, Dublin, Ireland). Lactobacillus mucosae DPC 6426 was enumerated on MRS supplemented with rifampicin $\left(100 \mathrm{mg} \cdot \mathrm{L}^{-1}\right.$, Sigma-Aldrich, Wicklow, Ireland). Random amplified polymorphic DNA (RAPD) PCR was performed on selected colonies to confirm identity of $L b$. mucosae DPC 6426, using the primer sequence (5'-GCTCGTATGTTGTGTGG-3') described in Navidghasemizad et al. (2013). Viable $S$. thermophilus and Lb. helveticus cells and NSLAB were enumerated in duplicate on M-17 agar supplemented with $0.5 \%$ lactose $\left(42^{\circ} \mathrm{C}\right.$; Terzaghi and Sandine, 1975), MRS pH $5.4\left(30^{\circ} \mathrm{C}\right)$, and Lactobacillusselective agar $\left(\mathrm{LBS}, 30^{\circ} \mathrm{C}\right)$, respectively. The $\mathrm{PAB}$ were enumerated on sodium lactate agar supplemented with kanamycin $\left(40 \mathrm{mg} \cdot \mathrm{L}^{-1}\right.$, Merck) after incubation at $30^{\circ} \mathrm{C}$ for $7 \mathrm{~d}$ (Drinan and Cogan, 1992). Finally, Lb. mucosae DPC 6426 were also enumerated in the whey at various time points during processing.

\section{Cheese Composition}

Grated cheese samples were analyzed in duplicate for salt content by a potentiometric method (International Dairy Federation, 1981), for fat content by the international standard method (International Dairy Federation, 1996) and for moisture content by oven-drying at $102^{\circ} \mathrm{C}$ for $5 \mathrm{~h}$ (International Dairy Federation, 1982). The $\mathrm{pH}$ of cheese was assessed by blending $12 \mathrm{~mL}$ of $\mathrm{H}_{2} \mathrm{O}$ with $20 \mathrm{~g}$ of grated cheese and measured by using a standard $\mathrm{pH}$ meter (Mettler Toledo MP220; British Standards Institution, 1976).

\section{Proteolysis}

$\% p H 4.6$ Soluble N/Total N. Concentration of nitrogen soluble at $\mathrm{pH} 4.6$ was determined in duplicate by the method of Fenelon et al. (2000a) using the macro-Kjeldahl method (International Dairy Federation, 1993) and was expressed as a percentage of total nitrogen (\% pH 4.6-SN/TN).

Free Amino Acids. Individual free AA (FAA) were determined on the $\mathrm{pH} 4.6$-soluble $\mathrm{N}$ extracts as described by Fenelon et al. (2000b, 2002) using a Jeol JLC-500V AA analyzer fitted with a Jeol $\mathrm{Na}^{+}$high performance cation exchange column (Jeol Ltd., Tokyo, Japan). The chromatographic analyses were conducted at $\mathrm{pH} 2.2$ on samples from d 1, 91, and 182. Results are expressed as parts per million $\left(\mathrm{mg} \cdot \mathrm{kg}^{-1}\right)$.

\section{Confocal Laser Scanning Microscopy}

Confocal laser scanning microscopy (CLSM) was performed as per London et al. (2014) with modifications for sample type. Briefly, the protein matrix was fluorescently dyed using Fast Green FCF (excitation $633 \mathrm{~nm}$; Sigma-Aldrich), polysaccharide was labeled by lectin Wheat Germ Agglutinin Alexafluor 555 conjugate (excitation 561nm; WGA; Invitrogen, BioSciences, Dublin, Ireland), and finally SYTO9 (excitation/emission maxima of 480/500 nm) was employed to label viable and nonviable forms of bacteria. The excitation wavelengths and emission detection were set in accordance to the maximum excitation/emission value of the fluorescent dyes. Mature Cheddar cheese was sampled and sectioned using a scalpel into roughly $10 \mathrm{~mm} \times 10 \mathrm{~mm} \times 2 \mathrm{~mm}$ sections and incubated at room temperature with the aforementioned labeling dyes applied to the surface. Images were acquired using the Leica TCS SP5 CLSM (Heidelberg GmbH, Mannheim, Germany), objective $63 \times$ (oil, Na 1.4) objective of a Leica TCS SP3 CLSM (Leica Microsystems, Heidelberg $\mathrm{GmbH}$ ).

\section{Texture Profile Analysis}

Two-bite texture profile analysis (TPA) was performed on uniformly cubed Cheddar cheeses on d 7, 70, 119, 154, and 182, as described by Costa et al. (2010). Swiss-type cheeses were excluded from TPA analysis because eye formation would confound results.

\section{Cheese Yield Calculation}

Sampling of milk, whey, and cheese were conducted as per Fenelon and Guinee (1999) and Guinee et al. 
(2006). In the case of Swiss-type cheeses, the individual components lost in the white whey were calculated by measuring moisture, fat, protein, and salt contents and the weights of cheeses pre- and postbrining and also allowing for the salt uptake during brining.

Yield analysis was undertaken as per Guinee et al. (2006) and included the following: Actual cheese yield $\left(\mathbf{Y}_{\mathrm{a}}\right)$, a unit of gross cheese conversion (i.e., kilograms of cheese obtained from $100 \mathrm{~kg}$ of cheese milk). This is calculated by weighing milk before cheese making and weight of cheese obtained following pressing for Cheddar and following brining for Swiss-type cheeses. In addition, $\mathrm{Y}_{\mathrm{a}}$ was normalized to levels of fat and protein present $\left(\mathbf{Y}_{\text {afpam }}\right)$ to negate intertrial variation. $Y_{\text {afpam }}$ negates the differences of different milk compositions to yield and thus allows comparisons between trials. $\mathbf{Y}_{\text {macy }}$ is a calculation adjusted for moisture content, allowing the yields of cheeses with different moistures to be compared. Finally, $\mathbf{Y}_{\text {macyfpam }}$ is the combined measurement of cheese yield adjusted for moisture and normalized for the fat and protein content of the cheese milk.

\section{Sensory Analysis}

Sensory analysis of both Swiss-type and Cheddar cheeses was performed by a trained sensory panel by affective evaluation and ranking descriptive analysis. Thirty Swiss cheese consumers and 26 Cheddar cheese consumers, aged 21 to $48 \mathrm{yr}$, were recruited for affective evaluation. Selection criteria for consumers were availability and motivation to participate on all days of the experiment. Consumers used the sensory hedonic descriptors in Appendix Table A1 for 2 different Swiss cheeses and 3 different Cheddar cheeses, presented in duplicate and triplicate, respectively. A further 10 Swiss cheese consumers and 12 Cheddar consumers, aged 21 to $48 \mathrm{yr}$, were recruited for ranking descriptive analysis. All panelists had previously participated in cheese descriptive profiles and were well versed in the sensory experimental protocol. Panelists were briefly trained using the sensory intensity descriptors in Appendix Table A1.

Sensory analysis was carried out in panel booths conforming to international standards (ISO 8589:2007). All samples were blast frozen to $-20^{\circ} \mathrm{C}$ then stored at $-20^{\circ} \mathrm{C}$ until analysis. Samples were then held at refrigeration temperatures overnight $\left(4^{\circ} \mathrm{C}\right)$, before monadic presentation to the naïve assessor panel at ambient temperatures $\left(\sim 21^{\circ} \mathrm{C}\right)$ and coded with a randomly selected 3-digit code. The cheese was immediately served to consumers. Each assessor was provided with deionized water and instructed to cleanse their palates between tastings. Additionally, each assessor was asked to indicate their degree of liking on a 10-cm line scale ranging from 0 (extremely dislike) at the left to 10 (extremely like) at the right and rating subsequently scored in centimeters from the left. The order of the presentation of all test samples was randomized to prevent first-order and carryover effects. The appearance attributes of Swiss-type cheeses were assessed in a separate session by 9 assessors, in triplicate.

\section{Statistical Analysis}

A split plot design, generated in SAS v9.3 (SAS Institute Inc., Cary, NC), was used to determine the effects of the adjunct culture on all textural, sensory, and biochemical variables at each time point throughout the ripening period. A time and treatment ANOVA was undertaken for all split plot data with a Tukey-Kramer adjustment, and differences were considered significant at an adjusted $P<0.05$. Regression and correlation analyses were performed on data using PASW Statistics v18.0 (IBM Corp., Chicago, IL).

\section{RESULTS AND DISCUSSION}

\section{Starter, PAB, NSLAB, and Adjunct Viability During Ripening}

Lactococcus lactis. All starter and adjunct cultures were subject to a $\sim 10$-fold concentration from cheese milk during curd formation and draining of whey. Mean viable counts of $L$. lactis were $10^{9.5}$ to $10^{10} \mathrm{cfu} \cdot \mathrm{g}^{-1}$ following Cheddar cheese manufacture and decreased significantly to $\sim 10^{8} \mathrm{cfu} \cdot \mathrm{g}^{-1}$ during ripening $(P<0.0001$; Figure 1a). The co-inoculation with $L b$. mucosae DPC 6426 had no significant effect on the growth of L. lactis at any time throughout ripening.

Streptococcus thermophilus. Streptococcus thermophilus was found at $\sim 10^{9} \mathrm{cfu} \cdot \mathrm{g}^{-1}$ in both Swisstype cheeses on d 1 (Figure 1b). Following this, St. thermophilus viability significantly decreased in both cheeses by d $21(P<0.05)$, after which point enumeration was ceased due to increased prevalence of NSLAB, which could confound counts. Lactobacillus mucosae DPC 6426 had no significant effect on the growth of St. thermophilus during ripening.

Lactobacillus helveticus. Mean viable counts of Lb. helveticus were $5 \times 10^{8} \mathrm{cfu} \cdot \mathrm{g}^{-1}$ at $\mathrm{d} 1$ and decreased significantly to $\sim 5 \times 10^{6} \mathrm{cfu} \cdot \mathrm{g}^{-1}$ during ripening of Swiss-type cheeses $(P<0.0001$; Figure 1c). Co-inoculation with $L b$. mucosae DPC 6426 had no significant effect on the growth of $L b$. helveticus at any time during ripening.

Propionic Acid Bacteria. Propionic acid bacteria were inoculated to Swiss-type cheese milk to achieve a 

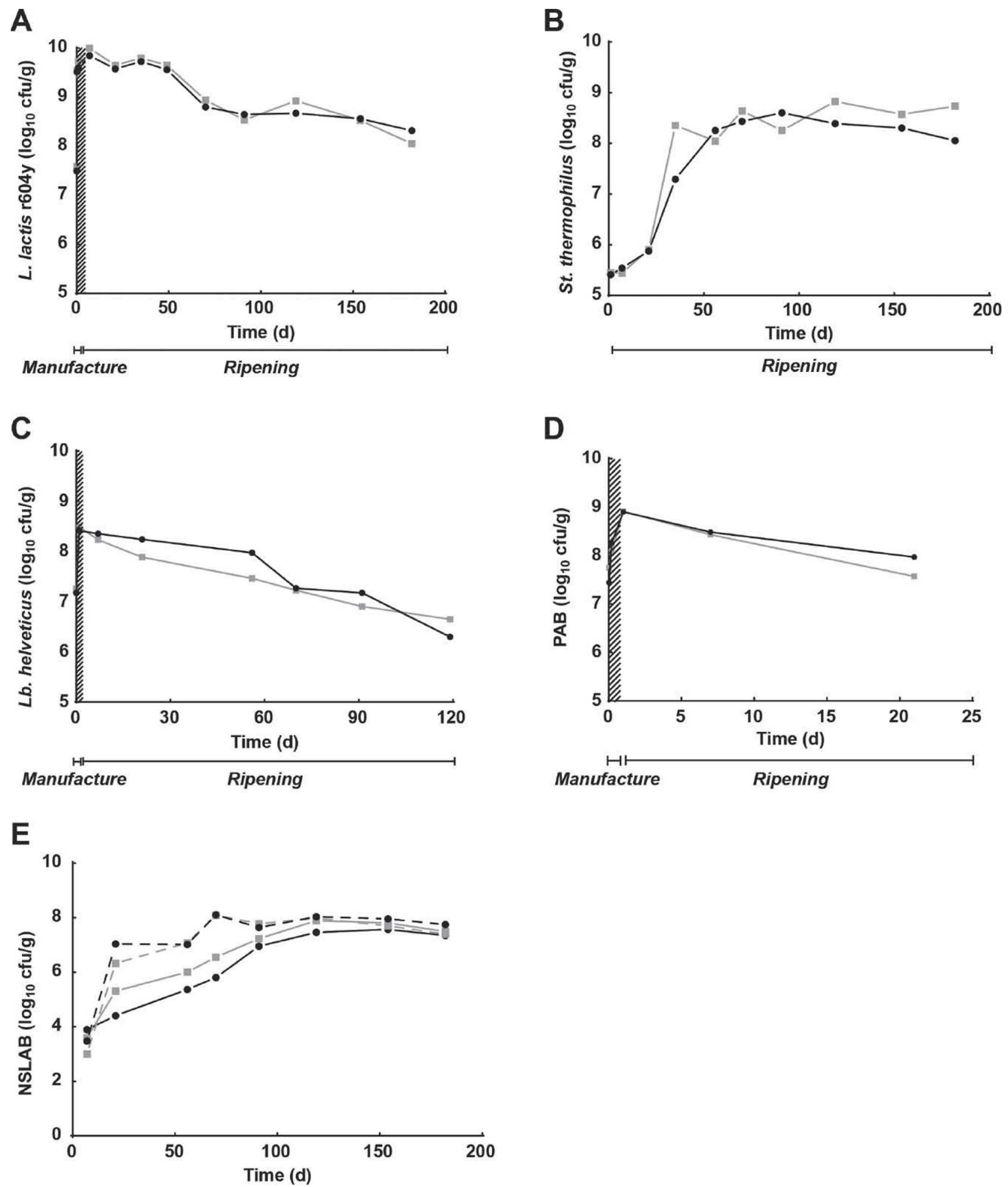

Figure 1. Starter and nonstarter lactic acid bacteria (NSLAB) counts. (A) Cheddar starter (Lactococcus lactis R604) counts of control (black circles) and adjunct (gray squares) over the ripening period. (B) Swiss-type St. thermophilus counts of control (black circles) and adjunct (gray squares) for the first $21 \mathrm{~d}$ of the ripening period. (C) Swiss-type Lb. helveticus counts of control (black circles) and adjunct (gray squares) for the first $119 \mathrm{~d}$ of the ripening period. (D) Propionic acid bacteria (PAB) counts of control (black circles) and adjunct (gray squares) Swisstypes over the ripening period. (E) NSLAB development in Swiss-type control (black circles and dashed line), adjunct (gray squares and dashed line), and Cheddar control (black circles and solid line) and adjunct (gray squares and solid line) cheeses. Shaded area represents counts during manufacture. 
mean viable count of $\sim 5 \times 10^{5} \mathrm{cfu} \cdot \mathrm{mL}^{-1}$ in cheese and remained unchanged from $d 1$ to 7 (Figure 1d). Thereafter, the cheeses entered hot-room ripening, resulting in $>2.5 \mathrm{log}$ increase for both control and adjunct cheeses to $\sim 10^{8} \mathrm{cfu} \cdot \mathrm{g}^{-1}$ by d $56(P<0.0001)$. Co-inoculation with $L b$. mucosae DPC 6426 had no significant effect on the viability of $\mathrm{PAB}$ at any time during ripening.

NSLAB. Nonstarter lactic acid bacteria were present in all cheeses $\left(<10^{4} \mathrm{cfu} \cdot \mathrm{g}^{-1}\right)$ at $\mathrm{d} 7$ and increased significantly over the ripening period to $\sim 5 \times 10^{8} \mathrm{cfu} \cdot \mathrm{g}^{-1}(P$ $<0.0001$; Figure 1e). Although not significant, NSLAB counts increased more dramatically between d 21 and 56 in Swiss-type cheeses than Cheddar, most likely due to the aforementioned hot step period. The presence of $L b$. mucosae DPC 6426 had no significant effect on NSLAB growth in comparison with control cheeses of both Swiss-type and Cheddar cheeses.

Lactobacillus mucosae DPC 6426. After inoculation into cheese milk, mean viable counts of $L b$. mucosae DPC 6426 were $10^{6} \mathrm{cfu} \cdot \mathrm{mL}^{-1}$ of cheese milk, with a subsequent 10-fold concentration in curd formation. During ripening, mean viable counts of the strain increased by a further $\log$ in Cheddar $(P<0.05)$ and remained viable at these levels after 6 mo of ripening at $8^{\circ} \mathrm{C}$ (Figure 2a). No significant change was found in mean viable counts of $L b$. mucosae DPC 6426 in Swisstype cheese during the entire ripening period. The milk fermentation and acidification potential of the adjunct strain, as assessed by iCinac (Unity Scientific, Brookfield, CT), was weak (data not shown), suggesting that Lb. mucosae DPC 6426 cannot grow well with lactose as the primary carbon source and may also have poor proteinase activity. This is in agreement with a previous Lb. mucosae DPC 6426 yogurt study, in which the strain was inoculated to milk at $4 \times 10^{8} \mathrm{cfu} \cdot \mathrm{mL}^{-1}$ and demonstrated no significant increase in mean viability over the $28-\mathrm{d} 4^{\circ} \mathrm{C}$ storage period (London et al., 2015a).

Overall, Cheddar rather than Swiss-type cheeses appeared a marginally more suitable matrix for $L b$. mucosae DPC 6426 as an adjunct culture. Whereas $L$. lactis growth was the most substantial of all primary and secondary starter bacteria, the starter has a reasonably narrow spectrum of metabolism (McSweeney and Sousa, 2000). In addition, galactose is known to be expelled during L. lactis lactose fermentation, left to be metabolized by the L. lactis population when lactose is depleted (Benthin et al., 1994). This may have given $L b$. mucosae DPC 6426 a period in the first $21 \mathrm{~d}$ of Cheddar ripening where galactose was available, allowing modest growth. Conversely, Swiss-type cheese, which was manufactured with St. thermophilus, Lb. helveticus, and $\mathrm{PAB}$, has a far more diverse microbial metabolic profile (Hutkins and Morris, 1987; Piveteau, 1999), indicat-
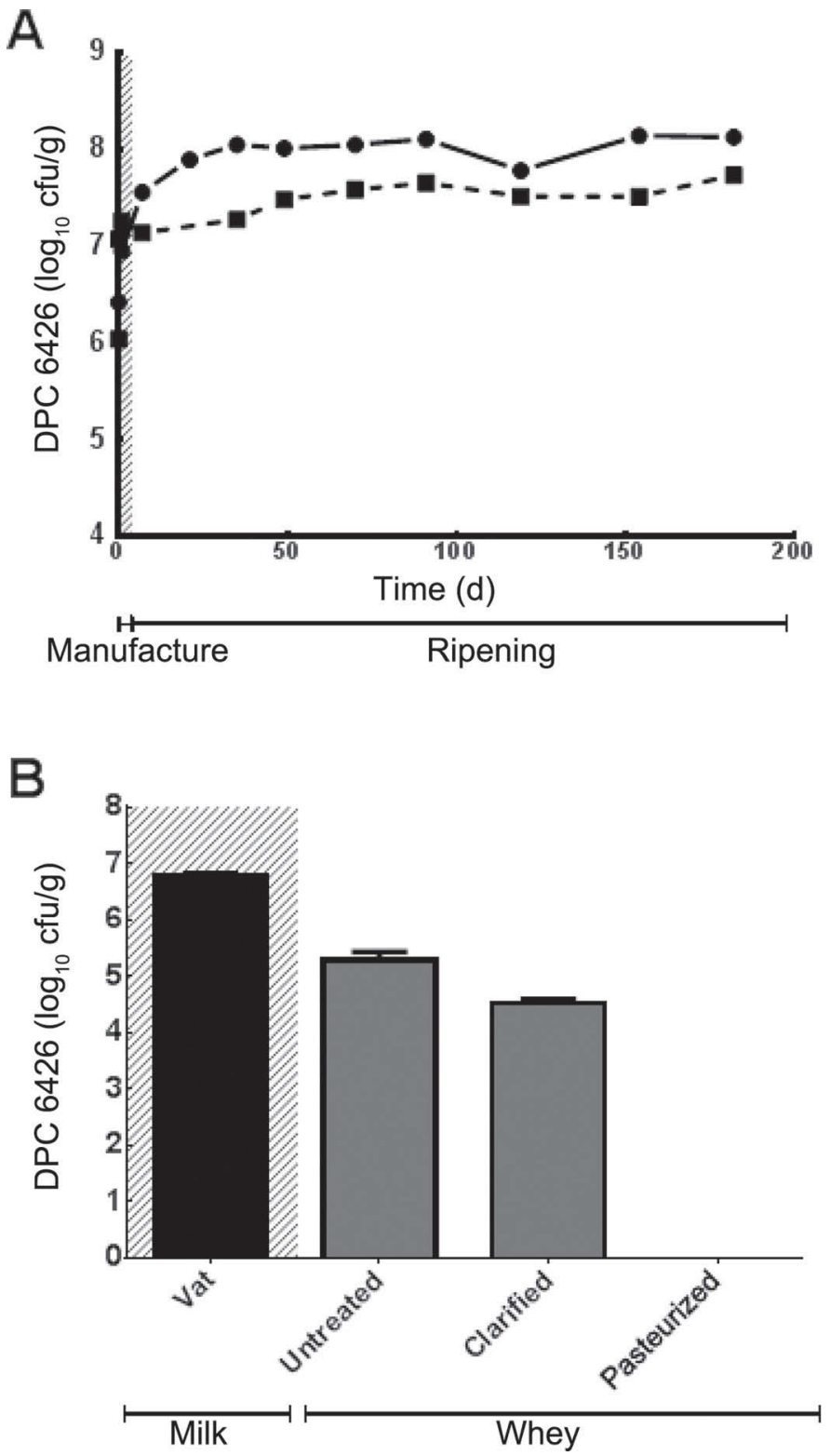

Figure 2. Adjunct survival counts. (A) DPC 6426 survival during ripening in Swiss-type (squares) and Cheddar (circles) cheese: shaded area represents counts during manufacture. (B) DPC 6426 survival in cheese whey during processing: shaded area represents counts in cheese milk.

ing competition for a more diverse selection of carbon sources. Finally, the high cooking temperature involved in Swiss-type cheese manufacture may have been responsible for injury and ultimately reducing viability of Lb. mucosae DPC 6426 (Sheehan et al., 2007a).

The influence of whey processing, including clarification, pasteurization, evaporation, and drying, on mean viable counts of $L b$. mucosae DPC 6426 was evaluated (Figure 2b). As has previously been reported for cheese 
starter bacteria (Jeanson et al., 2011; Doolan et al., 2014), less than $5 \%$ of the viable $L b$. mucosae DPC 6426 found in the cheese milk partitioned with the whey. It has previously been hypothesized that this is due to an affinity that bacteria show for milk fat globule and casein-fat interface (Laloy et al., 1996). Clarification of the whey is a centrifugal process in which much of the remaining milk fat globules will be drawn out (Byrne et al., 2002). As a result, this step incurred a log depletion of mean viable $L b$. mucosae DPC 6426 counts. The adjunct culture subsequently proved unable to survive pasteurization at any detectable levels.

\section{Cheese Composition}

Cheese composition at $\mathrm{d} 7$ of ripening is shown in Table 1. Full-fat Swiss-type and Cheddar cheese generally contain 32 and $30 \%$ fat, respectively. Swiss-type control and adjunct cheeses in the present study both achieved a $55 \%$ reduction in fat content compared with standard Swiss-type cheeses (Sheehan et al., 2008). Both control and adjunct-containing Cheddar cheese fat content were found to be $44 \%$ reduced from their full-fat counterparts (Chen et al., 1998). Fat content was dependent on cheese type, with Cheddar containing significantly more fat than Swiss-type $(P<0.0001)$. Protein content was similar to what has been previously reported for Swiss-type and Cheddar cheeses (Fenelon and Guinee, 2000; Costa et al., 2010). The presence of Lb. mucosae DPC 6426 had no significant effect on the protein or fat content of either cheese type.

Although both of the cheeses containing $L b$. mucosae DPC 6426 appeared to retain a slightly higher moisture content than control cheeses manufactured without the adjunct culture, our results indicate this was not statistically significant; despite the ability of the adjunct to produce up to $\sim 0.25 \mathrm{~g}$ of EPS per liter of yogurt (London et al., 2015a). However, this was not an entirely unexpected outcome. Previous research regarding the EPS-producing potential of Lb. mucosae DPC 6426 has indicated a significantly reduced EPS production efficacy when grown in the presence of lactose as the carbon source, compared with sucrose or glucose (London et al., 2011). The aforementioned yogurt was manufactured with $5 \%$ (wt/vol) sucrose in reconstituted skim milk, which was not possible in cheese manufacture, as this addition would greatly affect starter and NSLAB growth and metabolism.

The salt content and salt-in-moisture levels of reduced Cheddar and Swiss-type cheeses were similar to those reported previously (Sheehan et al., 2008; Costa et al., 2010), with Cheddar cheeses containing significantly more salt than Swiss-type cheeses $(P<0.01)$. The presence of $L b$. mucosae DPC 6426 did not significantly influence salt content or salt-in-moisture levels.

Lactobacillus mucosae DPC 6426 had no effect on the $\mathrm{pH}$ profiles of either cheese type both at $\mathrm{d} 7$ (Table 1) and during ripening (Figure 3). The $\mathrm{pH}$ for both control and adjunct Cheddar cheeses did not change significantly over the entire ripening period, whereas $\mathrm{pH}$ of both control and adjunct Swiss-type cheeses rose significantly $(P<0.0001)$. A positive correlation between $\mathrm{pH}$ and ripening time was observed for both adjunct-containing $\left(\mathrm{R}^{2}=0.99 ; P<0.0001\right)$ and control $\left(\mathrm{R}^{2}=0.98 ; P<0.0001\right)$ Swiss-type cheeses. This linear increase in $\mathrm{pH}$ is due to the metabolism of L-lactate by the growing $\mathrm{PAB}$ population producing propionate, acetate, and $\mathrm{CO}_{2}$ (McSweeney and Sousa, 2000).

Table 1. Mean composition of Swiss-type and Cheddar cheeses

\begin{tabular}{|c|c|c|c|c|}
\hline \multirow[b]{2}{*}{ Composition $^{1}$} & \multicolumn{2}{|c|}{ Swiss-type } & \multicolumn{2}{|c|}{ Cheddar } \\
\hline & Control & Adjunct & Control & Adjunct \\
\hline Fat (\% wt $/ w t)$ & $13.64^{\mathrm{a}}$ & $13.51^{\mathrm{a}}$ & $18.23^{\mathrm{b}}$ & $18.05^{\mathrm{b}}$ \\
\hline Moisture (\% wt/wt) & $39.31^{\mathrm{a}}$ & $39.51^{\mathrm{a}}$ & $39.57^{\mathrm{a}}$ & $40.31^{\mathrm{a}}$ \\
\hline FDM $(\%$ wt $/ w t)$ & $24.59^{\mathrm{a}}$ & $24.37^{\mathrm{a}}$ & $32.16^{\mathrm{b}}$ & $31.70^{\mathrm{b}}$ \\
\hline MNFS (\% wt/wt) & $51.05^{\mathrm{a}}$ & $51.40^{\mathrm{a}}$ & $52.89^{\mathrm{a}}$ & $53.32^{\mathrm{a}}$ \\
\hline Protein (\% wt/wt) & $35.66^{\mathrm{a}}$ & $35.38^{\mathrm{a}}$ & $33.43^{\mathrm{a}}$ & $33.62^{\mathrm{a}}$ \\
\hline Salt $(\% \mathrm{wt} / \mathrm{wt})$ & $1.13^{\mathrm{a}}$ & $1.24^{\mathrm{a}}$ & $1.69^{\mathrm{b}}$ & $1.70^{\mathrm{b}}$ \\
\hline $\mathrm{S} / \mathrm{M}(\% \mathrm{wt} / \mathrm{wt})$ & $2.57^{\mathrm{a}}$ & $2.78^{\mathrm{a}}$ & $3.92^{\mathrm{b}}$ & $4.10^{\mathrm{b}}$ \\
\hline $\mathrm{pH}$ at $\mathrm{d} 20$ & $5.56^{\mathrm{a}}$ & $5.52^{\mathrm{a}}$ & $5.24^{\mathrm{b}}$ & $5.23^{\mathrm{b}}$ \\
\hline $\mathrm{Y}_{\mathrm{a}}(\%)$ & $6.147^{\mathrm{a}}$ & $6.057^{\mathrm{a}}$ & $7.800^{\mathrm{a}}$ & $7.857^{\mathrm{a}}$ \\
\hline $\mathrm{Y}_{\text {macy }}(\%)$ & $5.593^{\mathrm{a}}$ & $5.467^{\mathrm{a}}$ & $7.200^{\mathrm{b}}$ & $7.173^{\mathrm{b}}$ \\
\hline $\mathrm{Y}_{\text {macypfam }}(\%)$ & $9.187^{\mathrm{a}}$ & $8.930^{\mathrm{a}}$ & $10.60^{\mathrm{a}}$ & $10.55^{\mathrm{a}}$ \\
\hline $\mathrm{Y}_{\text {afpam }}(\%)$ & $10.10^{\mathrm{a}}$ & $9.897^{\mathrm{a}}$ & $11.48^{\mathrm{a}}$ & $11.55^{\mathrm{a}}$ \\
\hline
\end{tabular}




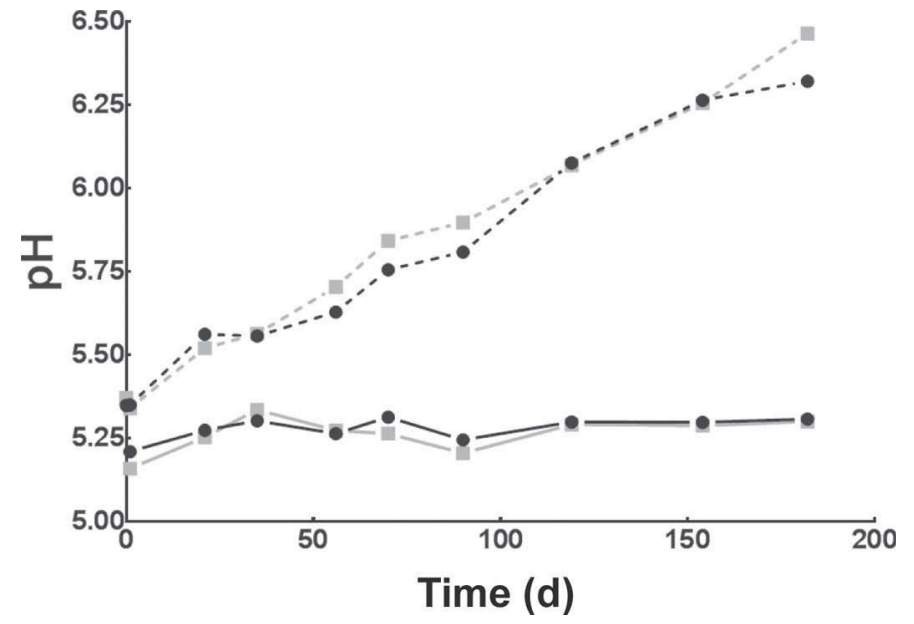

Figure 3. Mean pH profile of Cheddar control (black circles and solid line) and adjunct (gray squares and solid line) and Swiss-type control (black circles and dashed line) and adjunct (gray squares and dashed line) cheeses over $182 \mathrm{~d}$ of ripening.

\section{Proteolysis}

\% $\boldsymbol{p H}$ 4.6-SN/TN. Overall, the addition of $L b$. mucosae DPC 6426 had no significant effect on levels of $\mathrm{pH}$ 4.6-SN/TN during ripening. A significant increase $(P<0.0001)$ in $\% \mathrm{pH} 4.6-\mathrm{SN} / \mathrm{TN}$, which is indicative of primary proteolysis, was recorded for all cheeses over the ripening period (Figure 4). All cheeses finished ripening with between 20 and $25 \% \mathrm{pH} 4.6-\mathrm{SN} / \mathrm{TN}$, which is comparable with previously reports for such cheeses (Sheehan et al., 2008; Costa et al., 2010).

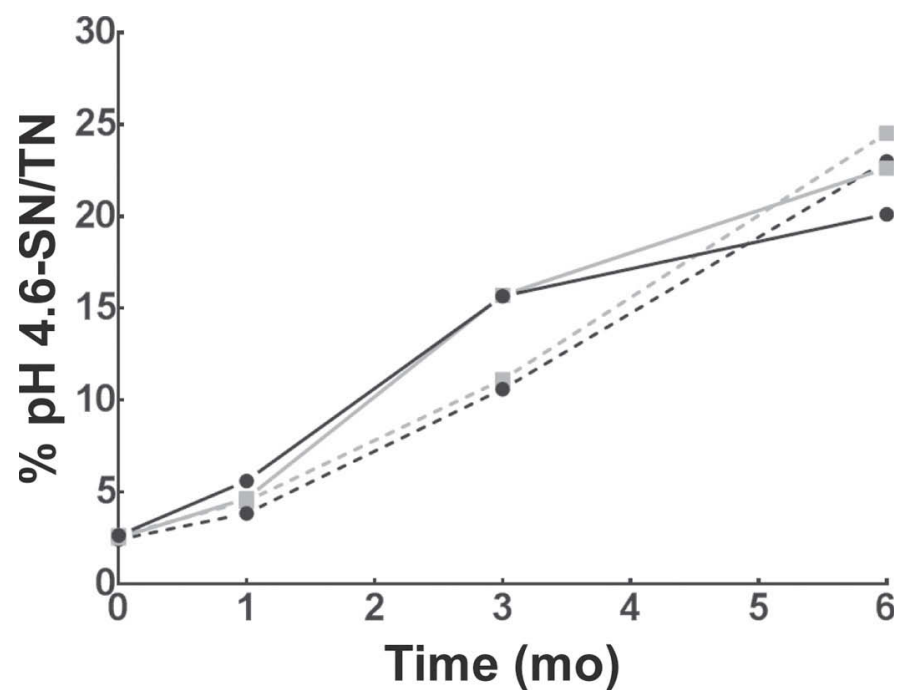

Figure 4. Ripening index. Percentage $\mathrm{pH} 4.6$ soluble nitrogen in Cheddar control (black circles and solid line) and adjunct (gray squares and solid line) and Swiss-type control (black circles and dashed line) and adjunct (gray squares and dashed line). Expressed as a percentage of total nitrogen.
Total FAA. A significant increase occurred in total FAA for both Swiss-type $(P<0.0001$; Figure 5a) and Cheddar $(P<0.001)$ cheeses during 6 mo of ripening from baseline. Total FAA levels in the ripened cheeses were comparable with previously reported values for each cheese type (Lawlor et al., 2002; Costa et al., 2010). Swiss-type cheeses were produced with $L b$. helveticus, a species known to harbor FAA-liberating intracellular peptidases, likely to account for the significant differences in total FAA between the 2 cheese types $(P$

A

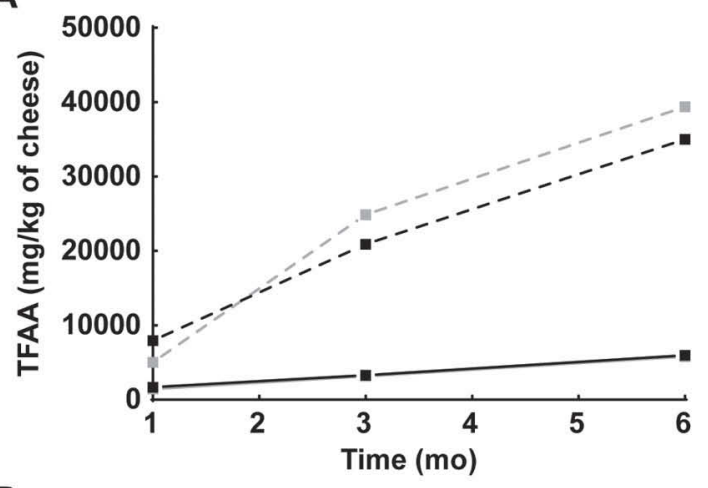

B

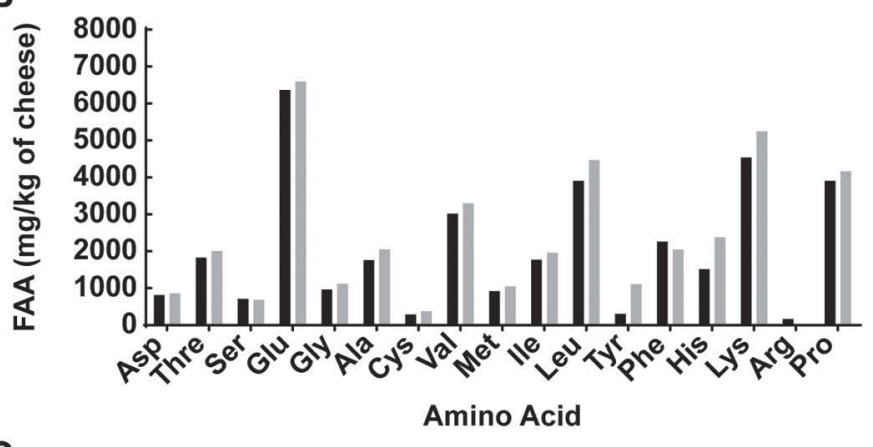

C

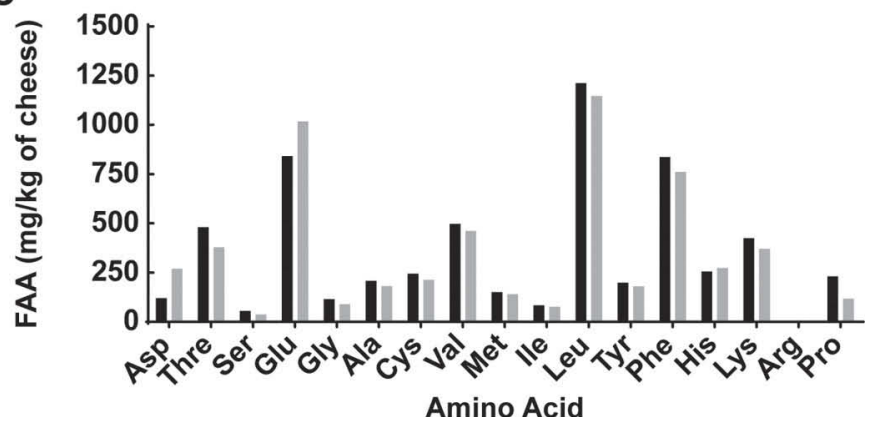

Figure 5. (A) Sum of total free AA in Cheddar control (black circles and solid lines) and adjunct (gray squares and solid lines) and Swiss-type control (black circles and dashed line) and adjunct (gray squares and dashed lines). Expressed as micrograms of AA per gram of cheese. (B) Free AA profile of Swiss-type control (black) and adjunct (gray) at 6 mo ripening. Expressed as microgram of AA per gram of cheese. (C) Free AA profile of Cheddar control (black) and adjunct (gray) at 6 mo ripening. Expressed as micrograms of AA per gram of cheese. 
$<$ 0.0001; Kenny et al., 2006). However, no significant differences were observed resulting from the addition of Lb. mucosae DPC 6426.

Individual FAA. The draft genome of $L b$. mucosae DPC 6426 implies several predicted peptidases, including putative methionine aminopeptidases and proline iminopeptidases (Ryan et al., 2015a). However, this was not reflected in the FAA profile, with no significant increases in methionine or proline at any time point in either adjunct-containing cheese types (Figures 5b and $5 \mathrm{c}$ ). Leucine, an AA associated with bitter taste, was previously found to be increased in cheeses manufactured with an EPS-producing adjunct (Awad et al., 2005); however, this was not noted in either adjunct containing Cheddar or Swiss-type cheeses. Arginine was found to be higher in the control Swiss-type cheese at 1 mo $(P<0.05$; data not shown $)$. By mo 3 , this difference had attenuated as arginine was almost entirely depleted in both cheeses, a process thought to be caused by NSLAB metabolism of the AA into $\mathrm{NH}_{3}$, ornithine, and citrulline (Laht et al., 2002). At mo 3, lysine was increased in the adjunct Swiss-type cheese compared with the control $(P<0.05$; data not shown). No significant differences were recorded between the Swiss-type cheeses at 6 mo (Figure 5b) or Cheddar cheeses at any time point $(P>0.05$; Figure $5 \mathrm{c})$.

\section{CLSM}

Although previous studies using CLSM have shown the presence of polysaccharide (EPS) in the crevices within the cheese protein matrix (Hassan et al., 2002), no significant accumulation was observed in this study (Figure 6). This is in agreement with the similarities found in moisture content of control and adjunctcontaining cheese, and indicates that $L b$. mucosae DPC 6426 did not produce significant amounts of EPS within the cheese matrix in the presence of lactose. It is hypothesized that the cholesterol-reducing effects of $L b$. mucosae DPC 6426 observed by London et al. (2015b) were at least in part due to EPS production. However, it should be noted that in this animal study the probiotic underwent several washing steps to eliminate nonmicrobial nutrients, a process that most likely removed much of the loosely associated EPS. Taken together, this suggests that much of the beneficial effects observed were the result of EPS or metabolites produced by the strain in vivo, in its native GIT ecosystem.

\section{Texture Profile}

Mean levels of hardness and chewiness decreased in both Cheddar control and adjunct-containing cheeses over the ripening period $(P<0.0001 ;$ Figure $7 \mathrm{a})$, as did cheese springiness $(P<0.0001$; Figure $7 \mathrm{~b})$. However, no significant differences were observed between control Cheddar cheeses and those containing $L b$. mucosae DPC 6426 in texture parameters at any time during ripening.

The general trend toward reduction in all TPA metrics during ripening may be due to the proteolytic breakdown of casein by remaining chymosin and the enzymes of starter, nonstarter, and adjunct LAB (Sousa et al., 2001; O'Mahony et al., 2005; Sheehan et al., 2007b). Reducing the fat content of cheeses invariably leads to an inherently harder and chewier product (Agrawal and Hassan, 2008; Lteif et al., 2009), which is the result of the tighter casein calcium-phosphate network which is formed (Mistry, 2001). The addition of EPS-producing adjunct cultures during cheese manufacture has previously been reported as a successful strategy in reducing this undesirable attribute (Awad et al., 2005; Dabour et al., 2006; Costa et al., 2010). Although moisture retention, as a result of an increase in cheese structure openness, has previously been implicated as the mechanism through which EPS-producing strains reduce hardness and chewiness (Dabour et al., 2006), no significant effect on moisture content was recorded for adjunct-containing cheeses in this study. The EPS cultures harnessed in previous research were of dairy origin and were solely intended to improve cheese quality; however, heart health promoting $L b$. mucosae DPC 6426 is native to the mammalian GIT and, as a result, does not favor lactose as a substrate for EPS production.

\section{Cheese Yields}

Cheddar $Y_{a}, Y_{\text {macypfam }}$, and $Y_{\text {afpam }}$ were all found to be comparable or slightly higher than what has previously been reported for reduced-fat Cheddars (Costa et al., 2010). However, no Cheddar cheese yield metric was significantly altered by the presence of $L b$. mucosae DPC 6426. The $Y_{\text {macy }}$ of Swiss-type cheeses were significantly higher than that of Cheddar cheeses. Nonetheless, inoculation with $L b$. mucosae DPC 6426 also had no effect on any Swiss-type cheese yield parameter.

\section{Sensory Analysis}

Cheddar. Hedonic sensory analysis of Cheddar cheeses revealed that control cheeses scored significantly higher for liking of aroma $(P<0.05$; Figure 8a). However, ranking descriptive analysis attributes were not significantly different for any of the attributes assessed (data not shown). 
Swiss-Type. Figure 8b displays Swiss-type hedonic analysis, in which the control cheese was scored significantly higher for overall acceptability $(P<0.05)$, although the magnitude of the difference was small. However, the $L b$. mucosae DPC 6426 containing cheese was found to have a significantly more appealing texture $(P<0.05)$. Descriptive analysis (Table 2$)$ revealed that the adjunct Swiss-type cheese scored significantly $(P<$ $0.05)$ higher than control for the bitter taste attribute, whereas no other descriptors were significantly different. However, as previously discussed, no individual AA associated with a bitter flavor (i.e., phenylalanine, tyrosine, and leucine) were significantly higher in either of the cheese types containing Lb. mucosae DPC 6426. Appearance ranking descriptive data revealed that the adjunct-containing Swiss-type cheese was rated higher than control for eye quality and also eye distribution $(P$ $<0.05$; Figure 8c). Lactobacillus mucosae are known obligate heterofermentative lactobacilli and, as such, can have an effect on eye formation through gas production (Marth and Steele, 2001; Quiberoni et al., 2008). None of the other descriptors were significantly different.

\section{CONCLUSIONS}

Two types of reduced-fat, semi-hard cheeses were manufactured in triplicate with and without the addition of an EPS-producing adjunct strain with beneficial heart health attributes, Lb. mucosae DPC 6426, and monitored for culture viability and product quality over

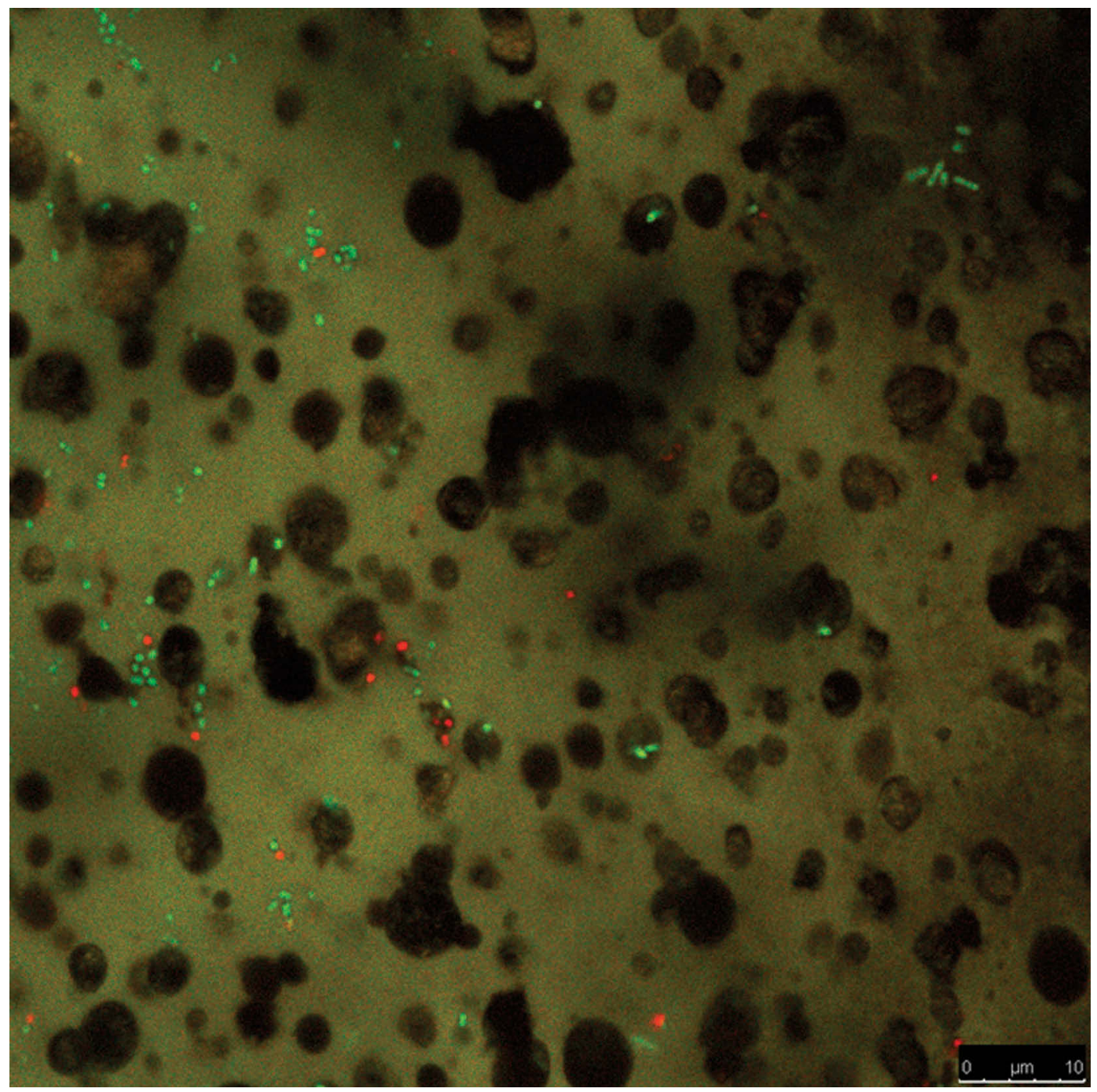

Figure 6. Confocal laser scanning microscopy. Adjunct Cheddar protein matrix stained with Fast Green and polysaccharide-staining Alexa Fluor 555, demonstrating lack of EPS in matrix pores or surrounding live (green) and dead (red) stained bacteria. Scale bar is $7.5 \mu \mathrm{m}$. 
A
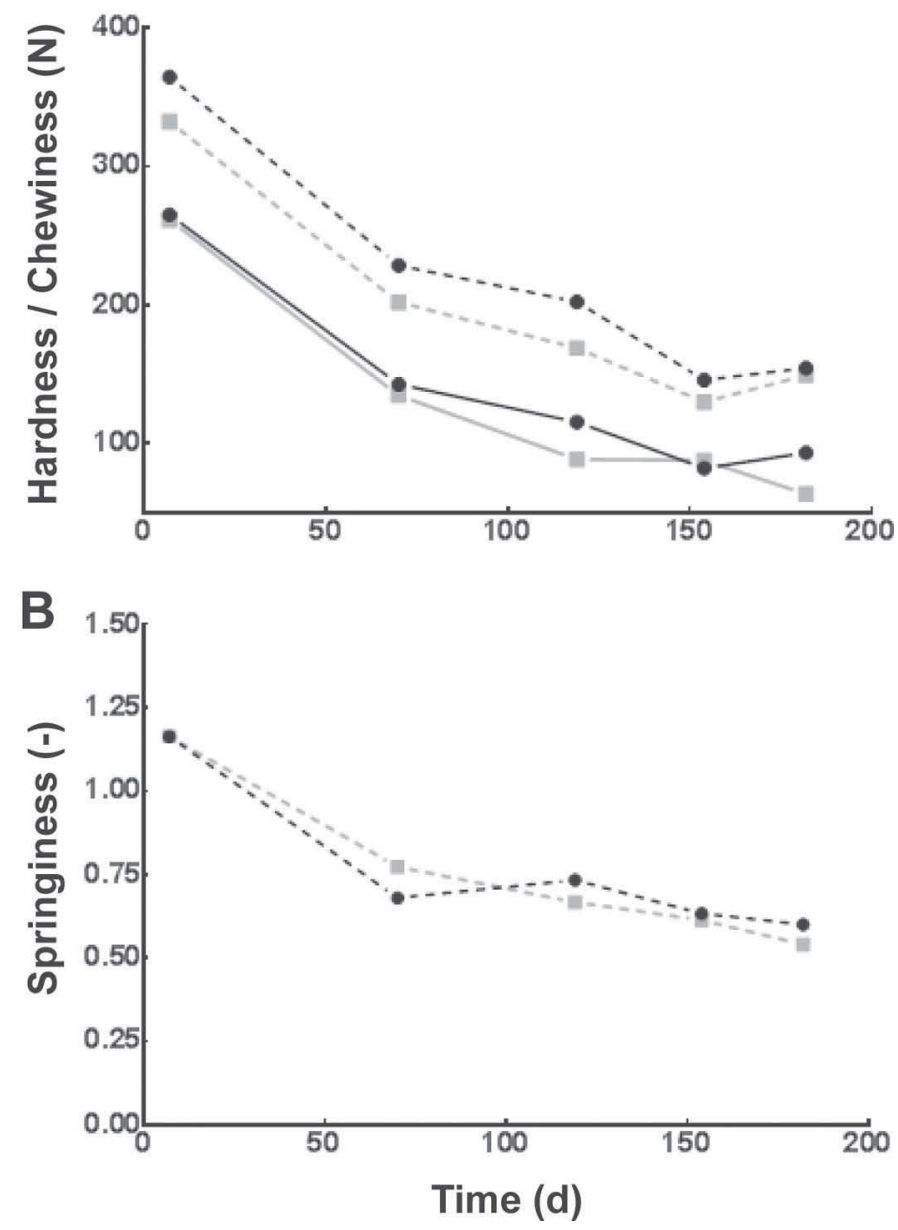

Figure 7. Cheddar texture profile. (A) Hardness of control (black circles and dashed line) and adjunct (gray squares and dashed line) and chewiness of control (black circles and solid line) and adjunct (gray squares and solid line) Cheddars over ripening period. (B) Cheddar control (black circles and dashed line) and adjunct (gray squares and dashed line) springiness over ripening period.

a 6-mo ripening period. Although Lb. mucosae DPC 6426 remained viable at high levels $\left(>5 \times 10^{7} \mathrm{cfu} \cdot \mathrm{g}^{-1}\right)$ over the 6-mo ripening period without imparting any negative attributes, the presence of the strain was not associated with any effect on sensory or textural quality of the cheeses. Whereas the beneficial heart health effects of Lb. mucosae DPC 6426 have been at least partly attributed to the EPS production ability of the strain, previous research implicates in vivo EPS production for efficacy. We can infer from this that, although the adjunct culture had little or no effect on cheese texture and composition, the probiotic cheese may still confer a heart health effect to the host. This study demonstrates that both reduced-fat Swiss-type and Cheddar cheeses are suitable functional food matrices for delivery of cholesterol-lowering Lb. mucosae DPC 6426.
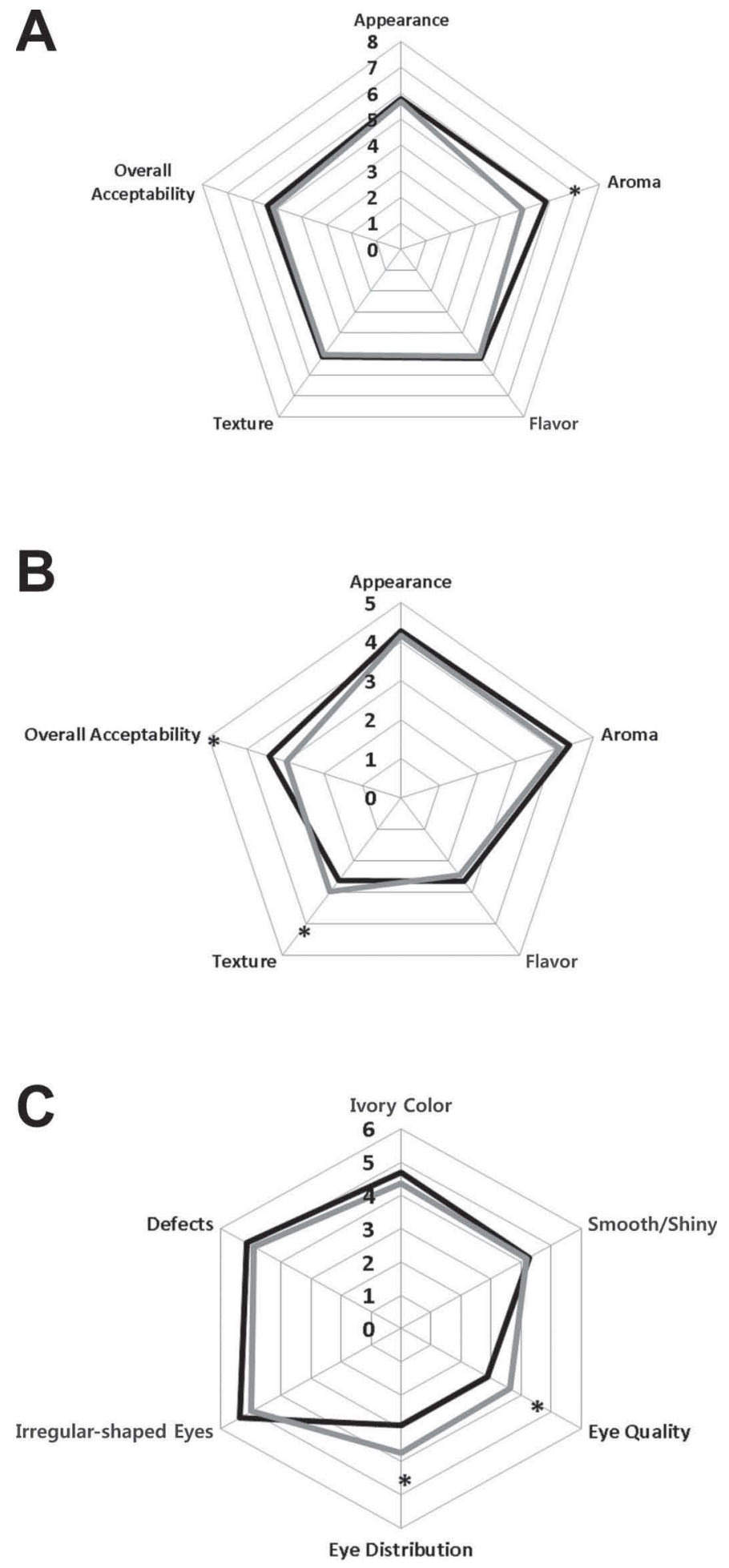

Figure 8. (A) Hedonic sensory analysis of control (black) and adjunct (gray) Cheddars. (B) Hedonic sensory analysis of control (black) and adjunct (gray) Swiss types. (C) Appearance analysis of control (black) and adjunct (gray) Swiss types. 
Table 2. Descriptive flavor of reduced-fat Swiss-type cheeses at 6 mo of ripening

\begin{tabular}{lcc}
\hline Item & Control & Adjunct \\
\hline Sweaty/sour & $4.49^{\mathrm{a}}$ & $4.91^{\mathrm{a}}$ \\
Dairy sweet & $4.44^{\mathrm{a}}$ & $4.10^{\mathrm{a}}$ \\
Nutty aroma & $3.10^{\mathrm{a}}$ & $2.81^{\mathrm{a}}$ \\
Pungent & $4.02^{\mathrm{a}}$ & $3.68^{\mathrm{a}}$ \\
Off & $2.12^{\mathrm{a}}$ & $2.39^{\mathrm{a}}$ \\
Diacetyl & $3.90^{\mathrm{a}}$ & $3.61^{\mathrm{a}}$ \\
Fruity estery & $3.24^{\mathrm{a}}$ & $3.24^{\mathrm{a}}$ \\
Creamy & $2.84^{\mathrm{a}}$ & $3.22^{\mathrm{a}}$ \\
Sweety taste & $3.81^{\mathrm{a}}$ & $3.66^{\mathrm{a}}$ \\
Salt & $2.47^{\mathrm{a}}$ & $2.75^{\mathrm{a}}$ \\
Sour taste & $3.42^{\mathrm{a}}$ & $3.74^{\mathrm{a}}$ \\
Bitter taste & $2.61^{\mathrm{a}}$ & $3.26^{\mathrm{b}}$ \\
Firmness in mouth & $3.99^{\mathrm{a}}$ & $4.02^{\mathrm{a}}$ \\
Rubbery texture & $2.02^{\mathrm{a}}$ & $2.08^{\mathrm{a}}$ \\
Smooth texture & $1.06^{\mathrm{a}}$ & $0.93^{\mathrm{a}}$ \\
Oily texture & $1.94^{\mathrm{a}}$ & $1.94^{\mathrm{a}}$ \\
Sticky texture & $1.17^{\mathrm{a}}$ & $1.17^{\mathrm{a}}$ \\
Nutty flavor & $3.57^{\mathrm{a}}$ & $3.13^{\mathrm{a}}$ \\
Off flavor & $2.67^{\mathrm{a}}$ & $2.77^{\mathrm{a}}$ \\
Dairy sweety flavor & $3.82^{\mathrm{a}}$ & $3.87^{\mathrm{a}}$ \\
Diacetyl flavor & $3.73^{\mathrm{a}}$ & $4.02^{\mathrm{a}}$ \\
Buttery flavor & $3.45^{\mathrm{a}}$ & $3.31^{\mathrm{a}}$ \\
Fruity estery flavor & $3.17^{\mathrm{a}}$ & $3.31^{\mathrm{a}}$ \\
\hline
\end{tabular}

${ }^{\mathrm{a}, \mathrm{b}}$ Means in a row with common superscripts do not differ $(P \geq 0.05)$.

\section{ACKNOWLEDGMENTS}

P. M. Ryan is in receipt of a Teagasc Walsh Fellowship. This work was supported by European Commission's Seventh Framework Programme (FibeBiotics FP7/2007-2013) under Grant Agreement no. 289517, Enterprise Ireland Commercialisation Fund (Contract CF/2013/3030A/B), and Science Foundation Ireland funded APC Microbiome Institute, Cork, Ireland. The technical assistance of Juliet Wiley for cheese manufacture, Paula O'Connor for amino acid analysis, and Maurice O'Sullivan (University College Cork) for hedonic and descriptive sensory analysis is gratefully acknowledged.

\section{REFERENCES}

Agrawal, P., and A. N. Hassan. 2008. Characteristics of reduced fat Cheddar cheese made from ultrafiltered milk with an exopolysaccharide-producing culture. J. Dairy Res. 75:182-188.

Awad, S., A. N. Hassan, and F. Halaweish. 2005. Application of exopolysaccharide-producing cultures in reduced-fat Cheddar cheese: Composition and proteolysis. J. Dairy Sci. 88:4195-4203.

Benthin, S., J. Nielsen, and J. Villadsen. 1994. Galactose expulsion during lactose metabolism in Lactococcus lactis ssp. cremoris FD1 due to dephosphorylation of intracellular galactose 6-phosphate. Appl. Environ. Microbiol. 60:1254-1259.

British Standards Institution. 1976. Chemical analysis of cheese. Part 5: Determination of $\mathrm{pH}$ value. British Standard 770.

Byrne, E. P., J. J. Fitzpatrick, L. W. Pampel, and N. J. TitchenerHooker. 2002. Influence of shear on particle size and fractal dimension of whey protein precipitates: Implications for scale-up and centrifugal clarification efficiency. Chem. Eng. Sci. 57:3767-3779.
Chen, M., J. Irudayaraj, and D. J. McMahon. 1998. Examination of full fat and reduced fat Cheddar cheese during ripening by Fourier transform infrared spectroscopy. J. Dairy Sci. 81:2791-2797.

Costa, N. E., J. A. Hannon, T. P. Guinee, M. A. Auty, P. L. McSweeney, and T. P. Beresford. 2010. Effect of exopolysaccharide produced by isogenic strains of Lactococcus lactis on half-fat Cheddar cheese. J. Dairy Sci. 93:3469-3486.

Dabour, N., E. Kheadr, N. Benhamou, I. Fliss, and G. LaPointe. 2006. Improvement of texture and structure of reduced-fat Cheddar cheese by exopolysaccharide-producing Lactococci. J. Dairy Sci. 89:95-110.

Dicks, L. T., M. Botha, B. Loos, and C. Smith. 2014. Adhesion of Lactobacillus reuteri strain Lr1 to equine epithelial cells and competitive exclusion of Clostridium difficile from the gastro-intestinal tract of horses. Ann. Microbiol. 65:1087-1096.

Doolan, I., A. Nongonierma, K. N. Kilcawley, and M. Wilkinson. 2014 Partitioning of starter bacteria and added exogenous enzyme activities between curd and whey during Cheddar cheese manufacture. Int. Dairy J. 34:159-166.

Drinan, F. D., and T. M. Cogan. 1992. Detection of propionic acid bacteria in cheese. J. Dairy Res. 59:65-69.

EFSA. 2010. EFSA Panel on Dietetic Products, Nutrition and Allergies. Scientific Opinion on the substantiation of health claims related to live yoghurt cultures and improved lactose digestion (ID 1143, 2976) pursuant to Article 13(1) of Regulation (EC) No 1924/2006. EFSA J. 8:1763.

Fenelon, M., and T. Guinee. 1999. The effect of milk fat on Cheddar cheese yield and its prediction, using modifications of the Van Slyke cheese yield formula. J. Dairy Sci. 82:2287-2299.

Fenelon, M. A., T. P. Beresford, and T. P. Guinee. 2002. Comparison of different bacterial culture systems for the production of reduced-fat Cheddar cheese. Int. J. Dairy Technol. 55:194-203.

Fenelon, M. A., and T. P. Guinee. 2000. Primary proteolysis and textural changes during ripening in Cheddar cheeses manufactured to different fat contents. Int. Dairy J. 10:151-158.

Fenelon, M. A., T. P. Guinee, C. Delahunty, J. Murray, and F. Crowe. 2000a. Composition and sensory attributes of retail Cheddar cheese with different fat contents. J. Food Compos. Anal. 13:13-26.

Fenelon, M. A., P. O'Connor, and T. P. Guinee. 2000b. The effect of fat content on the microbiology and proteolysis in cheddar cheese during ripening dairy foods. J. Dairy Sci. 83:2173-2183.

Frese, S. A., R. W. Hutkins, and J. Walter. 2012. Comparison of the colonization ability of autochthonous and allochthonous strains of lactobacilli in the human gastrointestinal tract. Adv. Microbiol. $2: 399-409$.

Guinee, T. P., B. T. O'Kennedy, and P. M. Kelly. 2006. Effect of milk protein standardization using different methods on the composition and yields of Cheddar cheese. J. Dairy Sci. 89:468-482.

Hassan, A. N., J. F. Frank, and K. B. Qvist. 2002. Direct observation of bacterial exopolysaccharides in dairy products using confocal scanning laser microscopy. J. Dairy Sci. 85:1705-1708.

Hill, C., F. Guarner, G. Reid, G. R. Gibson, D. J. Merenstein, B. Pot, L. Morelli, R. B. Canani, H. J. Flint, S. Salminen, P. C. Calder, and M. E. Sanders. 2014. Expert consensus document: The International Scientific Association for Probiotics and Prebiotics consensus statement on the scope and appropriate use of the term probiotic. Nat. Rev. Gastroenterol. Hepatol. 11:506-514.

Hutkins, R., and H. Morris. 1987. Carbohydrate metabolism by Streptococcus thermophilus: A review. J. Food Prot. 50:876-884.

International Dairy Federation. 1981. Cheese and processed cheese products - Determination of chloride content (potentiometer titration method). International Dairy Federation Standard 88A. International Dairy Federation, Brussels, Belgium.

International Dairy Federation. 1982. Cheese and processed cheeseDetermination of the total solids content. International Dairy Federation Standard 4A. International Dairy Federation, Brussels, Belgium.

International Dairy Federation. 1993. Milk determination of nitrogen content. Standard 20B. International Dairy Federation, Brussels, Belgium. 
International Dairy Federation. 1996. Milk: Determination of the fat content (Rose Gottlieb gravimetric method). International Standard 1d. International Dairy Federation, Federation, Brussels, Belgium.

Jeanson, S., J. Chadœuf, M. N. Madec, S. Aly, J. Floury, T. F. Brocklehurst, and S. Lortal. 2011. Spatial distribution of bacterial colonies in a model cheese. Appl. Environ. Microbiol. 77:1493-1500.

Kenny, O., R. J. FitzGerald, G. O'Cuinn, T. Beresford, and K. Jordan. 2006. Autolysis of selected Lactobacillus helveticus adjunct strains during Cheddar cheese ripening. Int. Dairy J. 16:797-804.

Laht, T.-M., S. Kask, P. Elias, K. Adamberg, and T. Paalme. 2002. Role of arginine in the development of secondary microflora in Swiss-type cheese. Int. Dairy J. 12:831-840.

Laloy, E., J.-C. Vuillemard, M. El Soda, and R. E. Simard. 1996. Influence of the fat content of Cheddar cheese on retention and localization of starters. Int. Dairy J. 6:729-740.

Lavermicocca, P. 2006. Highlights on new food research. Dig. Liver Dis. 38:S295-S299.

Lawlor, J. B., C. M. Delahunty, M. G. Wilkinson, and J. Sheehan. 2002. Relationships between the gross, non-volatile and volatile compositions and the sensory attributes of eight hard-type cheeses. Int. Dairy J. 12:493-509.

Lee, J. H., V. D. Valeriano, Y.-R. Shin, J. P. Chae, G.-B. Kim, J.-S. Ham, J. Chun, and D.-K. Kang. 2012. Genome sequence of Lactobacillus mucosae LM1, isolated from piglet feces. J. Bacteriol. 194:4766.

London, L. E., V. Chaurin, M. A. Auty, M. A. Fenelon, G. F. Fitzgerald, R. P. Ross, and C. Stanton. 2015a. Use of Lactobacillus mucosae DPC 6426, an exopolysaccharide-producing strain, positively influences the techno-functional properties of yoghurt. Int. Dairy J. 40:33-38.

London, L. E., A. H. Kumar, R. Wall, P. G. Casey, O. O'Sullivan, F. Shanahan, C. Hill, P. D. Cotter, G. F. Fitzgerald, R. P. Ross, N. M. Caplice, and C. Stanton. 2015b. Exopolysaccharide-producing probiotic lactobacilli reduced serum cholesterol and modified enteric microbiota in ApoE-deficient mice. J. Nutr. 144:1956-1962.

London, L. E., N. P. Price, P. Ryan, L. Wang, M. A. Auty, G. F. Fitzgerald, C. Stanton, and R. P. Ross. 2014. Characterization of a bovine isolate Lactobacillus mucosae DPC 6426 which produces an exopolysaccharide composed predominantly of mannose residues. J. Appl. Microbiol. 117:509-517.

London, L. E. E., G. F. Fitzgerald, R. P. Ross, and C. Stanton. 2011. Exploitation of exopolysaccharide producing lactobacilli for development of fermented functional foods. PhD Thesis. University College Cork, Ireland.

Lteif, L., A. Olabi, O. Kebbe Baghdadi, and I. Toufeili. 2009. The characterization of the physicochemical and sensory properties of full-fat, reduced-fat, and low-fat ovine and bovine Halloumi. J. Dairy Sci. 92:4135-4145.

Lynch, K. M., P. L. H. McSweeney, E. K. Arendt, T. Uniacke-Lowe, S. Galle, and A. Coffey. 2014. Isolation and characterisation of exopolysaccharide-producing Weissella and Lactobacillus and their application as adjunct cultures in Cheddar cheese. Int. Dairy J. 34:125-134.

Marth, E. H., and J. Steele. 2001. Applied Dairy Microbiology. CRC Press, Boca Raton, FL.

McSweeney, P. L. H., and M. J. Sousa. 2000. Biochemical pathways for the production of flavour compounds in cheeses during ripening: A review. Lait 80:293-324.

Mistry, V. V. 2001. Low fat cheese technology. Int. Dairy J. 11:413422 .

Navidghasemizad, S., T. M. Takala, T. Alatossava, and P. E. Saris. 2013. Proline iminopeptidase PepI overexpressing Lactobacillus casei as an adjunct starter in Edam cheese. Bioengineered 4:408.
O'Mahony, J. A., J. A. Lucey, and P. L. H. McSweeney. 2005. Chymosin-mediated proteolysis, calcium solubilization, and texture development during the ripening of Cheddar cheese. J. Dairy Sci. 88:3101-3114.

Piveteau, P. 1999. Metabolism of lactate and sugars by dairy propionibacteria: A review. Lait 79:23-41.

Quiberoni, A., D. Guglielmotti, and J. Reinheimer. 2008. New and classical spoilage bacteria causing widespread blowing in Argentinean soft and semihard cheeses. Int. J. Dairy Technol. 61:358-363.

Ramiah, K., C. A. van Reenen, and L. M. T. Dicks. 2008. Surfacebound proteins of Lactobacillus plantarum 423 that contribute to adhesion of Caco-2 cells and their role in competitive exclusion and displacement of Clostridium sporogenes and Enterococcus faecalis. Res. Microbiol. 159:470-475.

Roos, S., F. Karner, L. Axelsson, and H. Jonsson. 2000. Lactobacillus mucosae sp. nov., a new species with in vitro mucus-binding activity isolated from pig intestine. Int. J. Syst. Evol. Microbiol. 50:251-258.

Ryan, P. M., C. M. Guinane, L. E. E. London, P. Kelleher, G. F. Fitzgerald, N. M. Caplice, R. P. Ross, and C. Stanton. 2015a Genome sequence of the heteropolysaccharide-producing strain Lactobacillus mucosae DPC 6426. Genome Announc. 3.

Ryan, P. M., R. P. Ross, G. F. Fitzgerald, N. M. Caplice, and C. Stanton. 2015b. Sugar-coated: Exopolysaccharide producing lactic acid bacteria for food and human health applications. Food Funct. 6:679-693.

Rynne, N. M., T. P. Beresford, A. L. Kelly, and T. P. Guinee. 2004 Effect of milk pasteurization temperature and in situ whey protein denaturation on the composition, texture and heat-induced functionality of half-fat Cheddar cheese. Int. Dairy J. 14:989-1001.

Sheehan, J. J., M. A. Fenelon, M. G. Wilkinson, and P. L. McSweeney. 2007a. Effect of cook temperature on starter and non-starter lactic acid bacteria viability, cheese composition and ripening indices of a semi-hard cheese manufactured using thermophilic cultures. Int. Dairy J. 17:704-716.

Sheehan, J. J., J. C. Oliveira, A. L. Kelly, and P. L. H. Mc Sweeney. 2007b. Effect of cook temperature on primary proteolysis and predicted residual chymosin activity of a semi-hard cheese manufactured using thermophilic cultures. Int. Dairy J. 17:826-834.

Sheehan, J. J., M. G. Wilkinson, and P. L. H. McSweeney. 2008. Influence of processing and ripening parameters on starter, non-starter and propionic acid bacteria and on the ripening characteristics of semi-hard cheeses. Int. Dairy J. 18:905-917.

Sousa, M. J., Y. Ardö, and P. L. H. McSweeney. 2001. Advances in the study of proteolysis during cheese ripening. Int. Dairy J. 11:327345.

Terzaghi, B. E., and W. E. Sandine. 1975. Improved medium for lactic streptococci and their bacteriophages. Appl. Microbiol. 29:807813.

Valeriano, V. D., M. M. Parungao-Balolong, and D. K. Kang. 2014. In vitro evaluation of the mucin-adhesion ability and probiotic potential of Lactobacillus mucosae LM1. J. Appl. Microbiol. 117:485-497.

van den Tempel, T., J. K. Gundersen, and M. S. Nielsen. 2002. The microdistribution of oxygen in Danablu cheese measured by a microsensor during ripening. Int. J. Food Microbiol. 75:157-161.

Watanabe, M., H. Kinoshita, I. N. Huang, K. Eguchi, T. Tsurumi, Y. Kawai, H. Kitazawa, K. Kimura, N. Taketomo, D. Kikuchi, T. Sase, K. Miura, H. Ogawa, C. Shibata, A. Horii, and T. Saito. 2012. An adhesin-like protein, Lam29, from Lactobacillus mucosae ME-340 binds to histone H3 and blood group antigens in human colonic mucus. Biosci. Biotechnol. Biochem. 76:1655-1660. 
RYAN ET AL.

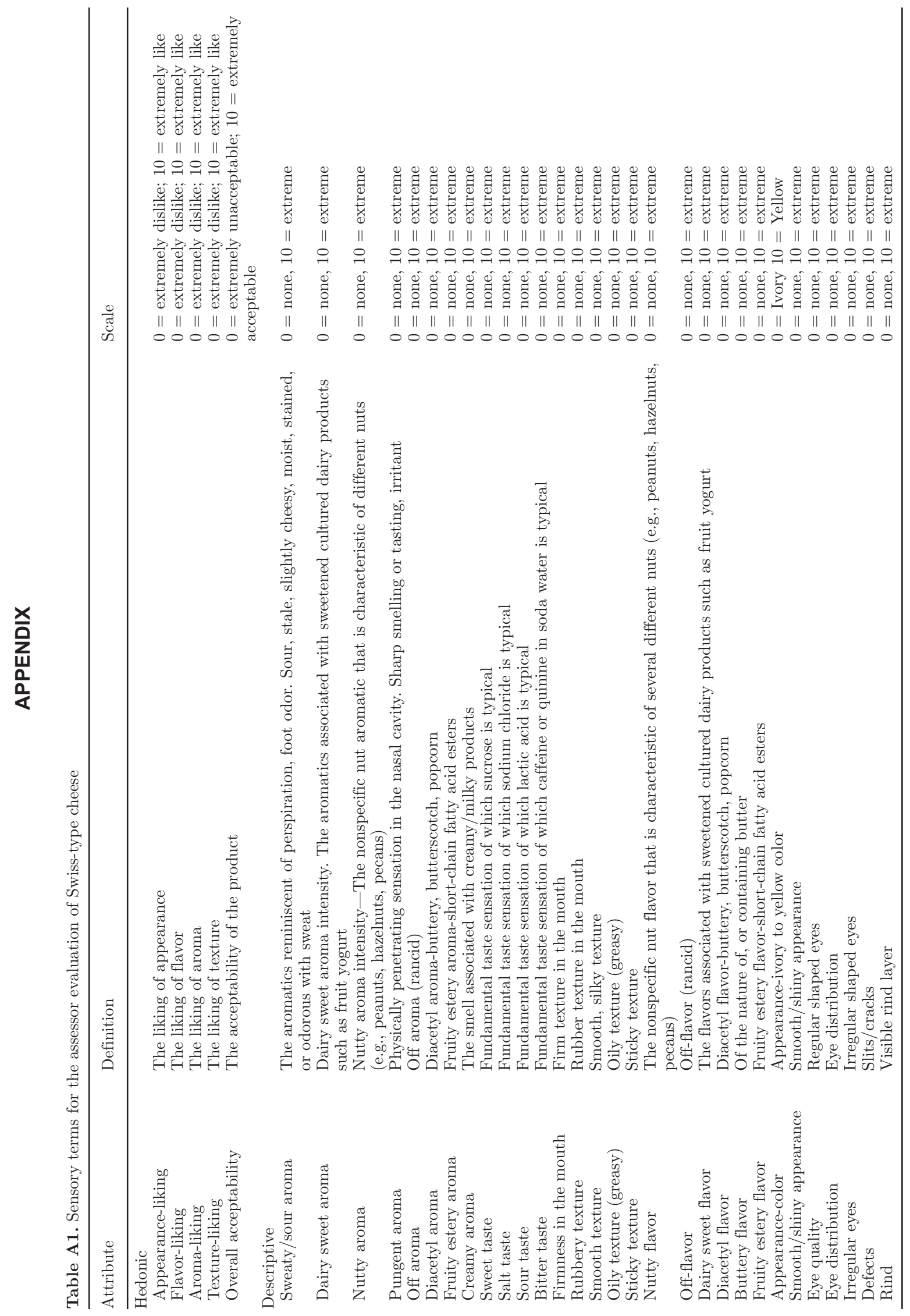

